\title{
QUANTIDADES DE SOLUÇÃo DE NITRATO DE POTÁSSIO E A GERMINAÇÃO DE SEMENTES DE Panicum maximum Jacq.
}

\author{
F.F. de TOLEDO; A.D.L.C. NOVEMBRE; H.M.C.P. CHAMMA \\ Departamento de Agricultura - ESALQ/USP, C.P. 9, CEP: 13418-900 - Piracicaba,SP
}

\begin{abstract}
RBSUMO: Realizou-se o presente trabalho com o objetivo de estudar a germinagão de sementes de cultivares de Paricum maximum Jacq. (Coloniāo, Tobiatã, Centenário, Centauro e Tanzânia), em testes sobre substratos umedecidos com três quantidades de soluçāo de nitrato de potássio a 0,2\%, quais sejam: 12, 16 e $20 \mathrm{ml}$. Depois de semeados, os gerboxes foram fechados com fita crepe e levados para germinador. As contagens de germinação foram realizadas de 7 em 7 dias, sem se acrescentar agua, e os gerboxes mantidos vedados. Os resultados permitiram concluir que houve diferença entre os testes, dependendo da quantidade de soluçăo utilizada, tendo a germinação com $12 \mathrm{ml}$ superado a das demais.
\end{abstract}

Deacritorea: Panicum sp., germinação, quantidades de $\mathrm{KNO}_{3}$

\section{QUANTTTES OF POTASSIUM NTTRATE SOLUTION AND THE GERMINATION OF Ponicum maximum Jacq. SEEDS}

\begin{abstract}
ARSTRACT: This work was carried out to study the germination of Panicum maximum Jacq. seeds, Colonião, Tohiatã, Centenário, Centauro and Tamzânia varieties, on substrata moistened with three different volumes of $0.2 \%$ potassium nitrate solution: 12,16 and $20 \mathrm{ml}$. After sowing, the gerbox covers were tied with tape and no water was added. Germination counts were done each 7 days. The germination test results pointed out that there were differences among them, depending on the amount of solution applied. The germination percentage with $12 \mathrm{ml}$ of solution applied to the substrata was greater than for the others.
\end{abstract}

$\mathrm{K}$ ey Words: Panicum sp., germination, $\mathrm{KNO}_{3}$ quantities

\section{INTRODUÇÃO}

Pesquisas conduzidas nos últimos vinte anos têm demonstrado a grande importância de se dosar, com rigor, a quantidade (volume) de água ou de nitrato de potássio adicionada ao substrato dos testes laboratoriais de germinação, para se realizar a avaliação da qualidade de lotes de sementes destinadas ao comércio. Sabe-se que existem materiais vegetais muito sensíveis ao excesso de umedecimento, enquanto outros não respondem de modo significativo a tal condição do substrato.

Ultimamente, com o lançamento de novos cultivares de $\boldsymbol{P}$. maximum Jacq., ou sejam Tobiatã, IAC-Centenário, IAC-Centauro, Tanzânia, os analistas dos laboratórios de empresas produtoras de sementes têm se mostrado preocupados com as variações observadas nos resultados entre repetições de um mesmo teste, bem como, com o mau desempenho de lotes que foram bem manejados durante as fases de produção, colheita, secagem, beneficiamento e armazenagem.
Diversas hipóteses têm sido aventadas a fim de explicar esses fatos, avultando-se entre elas a relacionada com a variação do umedecimento do papel usado nos testes de germinação.

Pelos motivos expostos, foi conduzido o presente trabalho que teve por objetivo avaliar o desempenho de sementes de cultivares de P.maximum Jacq. submetidas, periodicamente, a testes de germinação, nos quais foram empregadas quantidades distintas de solução de nitrato de potássio no substrato. As Regras para Análise de Sementes (BRASIL, 1985), utilizadas até há poucos anos, não abordavam de maneira detalhada a técnica prescrita para o umedecimento do substrato dos testes de germinação, que se apresentava nos seguintes termos: "o substrato, especialmente o de papel e para sementes pequenas, nunca deve ser tão molhado a ponto de formar uma película d'água em torno das sementes". Foram, entretanto, publicadas novas Regras (BRASIL, 1992) que tratam o assunto com mais propriedade, demonstrando a sua importância. 
Por outro lado, a literatura consultada permitiu observar que esta matéria há muito tempo vem causando preocupação aos pesquisadores. STILES (1949), trabalhando com várias espécies cultivadas, concluiu que elas exigiram diferentes quantidades de água para apresentar germinação satisfatoria. DELOUCHE(1960) cita que diferentes volumes de água fornecidos ao substrato a responsabilidade pela variação de resultados de germinação. Destacou, ainda, o fato de outro autor constatar grande sensibilidade das sementes as condições de umidade do substrato e encontrar os melhores resultados em papel chupão mantido em nível d'água inferior ao usado correntemente nos laboratórios que conhecia. COLLIS GEORGE \& SANDS (1961), trabalhando com aveia, alfafa e azevém, encontraram grande variação entre os testes de germinação, que foi atribuida a inconsistência do regime de umidade. VICENTE $e t$ al. (1969) estudando a embebição e a germinação de sementes de arroz, feijão e milho, relataram que as duas últimas espécies completaram a embebição com maior rapidez sob disponibilidade de umidade superior àquela $\mathrm{em}$ que apresentaram melhor germinação, enquanto para o arroz o menor foi melhor para embebição e germinação. PETERSON \& COOPER (1979) citam elevada variabilidade nas características de umidade dos substratos usados em dezoito laboratórios. A partir dos estudos conduzidos sugeriram pesquisas com o objetivo de determinar quantidade d'agua adequada para cada espécie e, como alternativa, o uso da técnica de saturar o substrato e drenagem completa do excesso antes de se distribuir as sementes, visando obter condições relativamente uniformes. Segundo ENGELHARDT et al. (1966) sementes de milho apresentaram altas porcentagens de germinação em ampla faixa de disponibilidade de água. BELCHER (1974) chegou a resultados semelhantes com diversas espécies do gênero Abeto. Testando distintos substratos com sementes de arroz, NORONHA et al. (1967) verificaram que houve necessidade de se administrar distintas quantidades de água para se chegar a porcentagens de germinação equivalentes entre si. BELCHER (1975), por outro lado, observou que a quantidade de água não é a mesma para diferentes substratos, a fim de se obter regularidade da germinação em uma determinada especie. PHANENDRANATH (1980), com o objetivo de avaliar os resultados dos testes de germinação de sorgo e milho, aplicou água equivalente a duas, duas e meia e tres vezes - peso do papel: observou que a menor quantidade propiciou a máxima germinação e, à medida que maiores quantidades foram adicionadas, a germinação decrescia. USBERTI (1981), fazendo consideraçōes sobre a germinação de capim Colonião, relatou que "comerciantes de sementes e pecuaristas afirmam que a porcentagem de germinação em condições de campo, em geral, é superior aquela observada em laboratorios de análise de rotina". TOLEDO \& PEDREIRA (1984), pesquisando com capim Colonião, tamberm verificaram que o uso de teores elevados de solução de nitrato de potássio causou efeito negativo nos resultados dos testes de germinação. De acordo com MARCOS FILHO et al. (1987), trabalhos desenvolvidos nos últimos anos mostraram respostas mais consistentes quando a umidade foi controlada através do cálculo baseado nas relações entre a quantidade de água usada e o peso de substrato.

Realizando ensaios de germinação com lotes de sementes de pepino de alta qualidade, EIRA \& BARROS (1987) não encontraram respostas entre os diferentes níveis de umidade usados nos substratos. Entretanto, TOLEDO \& CARVALHO (1990), testando sementes de Brachiaria brizantha, $B$. ruziziensis e $B$. decumbens, sob vários volumes de solução de nitrato de potássio, concluíram que as maiores quantidades de solução foram prejudiciais às duas primeiras especies, o mesmo não acontecendo com a terceira. Por sua vez TANAKA et al. (1991) verificaram que um lote de sementes de amendoim de alta capacidade de germinação se mostrou sensível à variação do conteúdo de água do substrato.

Em vista dos fatos relatados e a importancia que representam para a tecnologia e para a indústria nacional de sementes $\mathrm{e}$, no caso das forrageiras, para pecuária do País, foi estudado - comportamento da germinação de novos cultivares de Panicum maximum Jacq., sob diferentes quantidades de solução de ritrato de potássio empregadas no substrato.

\section{MATERIAL E METODOS}

Amostras de sementes recém-colhidas de cinco cultivares de $\boldsymbol{P}$. maximum Jacq., Colonião, Tobiatã, IAC-Centenário, IAC-Centauro e Tanzânia, obtidas de empresas produtoras localizadas na região noroeste do Estado de São Paulo, foram transportadas para o Laboratório de Sementes do Departamento de Agricultura da ESALQ/USP, 
Piracicaba. Nesse local, foram armazenadas em condições normais de ambiente e utilizadas no presente trabalho. As sementes dos referidos materiais, foram submetidas a testes de germinação em aparelho da marca Fanem, modelo 348-G, com controle automático de alternância de temperatura e luz. Como substrato empregou-se o papel chupão germibox, cortado em folhas de aproximadamente $11 \times 11 \mathrm{~cm}$, cujos pesos ajustou-se em balança analítica para 3,0 $\mathrm{g}$ cada uma. Duas folhas de 3,0 g, dispostas em cada gerbox, receberam solução de nitrato de potássio a $0,2 \%$, conforme os tratamentos da TABELA 1.

Depois do umedecimento e da semeadura, os gerboxes foram fechados com fita crepe gomada e levados para o aparelho Fanem. Em seqüência observou-se os demais procedimentos estabelecidos pela Regras para Análise de Sementes (BRASIL, 1985).

A solução de nitrato de potássio utilizada foi preparada, em cada época, com sal puro pró-análise e água destilada.

TABELA 1. Volume de solução de nitrato de potássio a $0,2 \%$ utilizado em cada tratamento.

\begin{tabular}{lc}
\hline Tratamento & $\begin{array}{c}\text { Volume de solução } \\
\text { (ml) }\end{array}$ \\
\hline 1 & 12 \\
2 & 16 \\
3 & 20 \\
\hline
\end{tabular}

Os testes de germinação, realizados a intervalos de 4 meses, prolongaram-se, aproximadamente, por dois anos, objetivando a obtenção de dados sobre o comportamento das sementes recém-colhidas (no início da pesquisa) e das mesmas durante seu envelhecimento.

Procedeu-se à análise estatística das porcentagens de germinação transformadas [ $(x=$ arc sen $\left.(\% / 100)^{1 / 2}\right]$, separadamente para cada cultivar, conforme delineamento completamente ao acaso, e as médias foram comparadas pelo teste de Tukey à $5 \%$ de probabilidade (PIMENTEL GOMES, 1978).

\section{RESULTADOS E DISCUSSÃO}

A análise da variância, para cada cultivar, apresentou valores significativos de $F$ entre quantidades de solução de nitrato de potássio. Em vista deste fato, foi aplicado o teste de Tukey, para comparação de médias, cujos resultados se encontram na TABELA 2.

TABELA 2. Médias dos resultados dos testes de germinação de 5 cultivares de $P$. maximum, sob 3 níveis de solução de $\mathrm{KNO}_{3}$ a $0,2 \%$.

\begin{tabular}{lccc}
\hline Cultivares & \multicolumn{3}{c}{ Tratamentos } \\
\hline & $12 \mathrm{ml}$ & $16 \mathrm{ml}$ & $20 \mathrm{ml}$ \\
& $(1)$ & $(1)$ & $(1)$ \\
\hline Colonião & $47,76 \mathrm{a}$ & $31,21 \mathrm{~b}$ & $23,27 \mathrm{~b}$ \\
Tobiatã & $48,92 \mathrm{a}$ & $43,14 \mathrm{ab}$ & $30,93 \mathrm{~b}$ \\
Centenário & $55,71 \mathrm{a}$ & $41,93 \mathrm{~b}$ & $30,67 \mathrm{c}$ \\
Centauro & $78,43 \mathrm{a}$ & $64,46 \mathrm{~b}$ & $58,21 \mathrm{~b}$ \\
Tanzânia & $28,50 \mathrm{a}$ & $18,59 \mathrm{~b}$ & $13,72 \mathrm{~b}$ \\
\hline
\end{tabular}

(1) Médias originais em porcentagem.

(2) Médias, na mesma linha, seguidas pela mesma letra, não diferem estatisticamente entre si, pelo Teste de Tukey em nível de $5 \%$ de probabilidade.

a) Cultivar Colonião: Os resultados dos testes realizados em 6 épocas distintas, an longo de 22 meses (TABELA 2), mostraram que o tratamento com $12 \mathrm{ml}$ de solução de nitrato de potássio a $0,2 \%$, aplicado no substrato, apresentou germinação superior à das outras duas quantidades usadas, enquanto que estas não diferiram estatisticamente entre si. Estes resultados são concordantes com os obtidos por TOLEDO \& PEDREIRA (1984), pesquisando com o próprio Colonião, e, também, com TOLEDO \& CARVALHO (1990) quando ensaiaram sementes de Brachiaria brizantha Stapf. e Brachiaria ruziziensis Stapf. Em vista desses fatos, acredita-se que 16 e $20 \mathrm{ml}$ sejam volumes inadequados, que provavelmente dificultam o processo respiratório aeróbico durante a germinação. PHANENDRANATH (1980) trabathando com milho e sorgo, e TANAKA et al. (1991) testando sementes de amendoim, verificaram que o excesso de umedecimento do substrato, somente com água, também se mostrou nefasto à germinação dessas espécies. Há, todavia, dados na literatura que não se alinham com estes. Por exemplo, EIRA \& BARROS (1987), pesquisando com lotes de sementes de ervilha, não observaram diferenças relacionadas com os diversos teores de água que acrescentaram no substrato. TOLEDO \& CARVALHO (1990) chegaram a resultados seme- 
lhantes com Brachiaria decumbens Stapf, usando solução de nitrato de potássio.

b) Cultivar Tobiata: As sementes deste cultivar mostraram ser mais tolerantes ao aumento da quantidade de solução no substrato, quando comparado com o anterior, pois não houve diferença estatística significativa entre os tratamentos com 12 e $16 \mathrm{ml}$, como, também, não foi observada entre 16 e 20 $\mathrm{ml}$, porém o tratamento com $12 \mathrm{ml}$ propiciou melhor germinação que $20 \mathrm{ml}$ (TABELA 2).

c) Cultivar Centenário: As sementes deste Panicum, do mesmo modo que Colonião, germinaram melhor sob o tratamento de $12 \mathrm{ml}$, mas mostraram maior sensibilidade ao aumento da quantidade de solução do que os dois primeiros, uma vez que, com $20 \mathrm{ml}$, o resultado obtido foi significativamente inferior ao proporcionado por $16 \mathrm{ml}$ (TABELA 2).

d) Cultivares Centauro e Tanzania: o comportamento das sementes destes materiais apresentou semelhança ao observado com o do Colonião, ou seja, a quantidade de $12 \mathrm{ml}$ de solução favoreceu a germinação em comparação com 16 e $20 \mathrm{ml}$, tratamentos estes que não diferiram entre si (TABELA 2).

\section{CONCLUSÕES}

a) As sementes dos cultivares testados germinaram melhor quando usou-se $12 \mathrm{ml}$ de solução de nitrato de potássio no substrato, salvo o Tobiatã que apresentou comportamento equivalente com $16 \mathrm{ml}$.

b) O Tobiatã revelou maior tolerância ao aumento da quantidade de solução aplicada no substrato de germinação.

c) O Centenário apresentou maior sensibilidade à aplicação de $20 \mathrm{ml}$ de solução.

d) Colonião, Centauro e Tanzânia mostraram comportamento muito semelhante entre si, quanto à resposta aos volumes de solução aplicados no substrato.

\section{REFERENCIAS BIBLIOGRAFICAS}

BELCHER, E.W. Influence of substrate moisture level on germination of four Picea spp. Proceedings of Association Seed Analysis of North America, Oklahoma City, v.64, p.129-130, 1974.
BELCHER, E.W. Influence of substrate moisture level on germination of four Picea spp. Seed Science \& Technology, Zurich, v.3, n.3/4, p.597-604, 1975.

BRASIL. Ministério da Agricultura. Departamento da Produção Vegetal. Divisāo de Sementes e Mudas. Regras para Anslise de Sementes. Brasilia, 1985. 185p.

BRASIL. Ministério da Agricultura e Reforma Agrária. Departamento Nacional de Defesa Vegetal. Coordenaçũo de Laboratório Vegetal. Regras para Andilise de Sementes. Brasilia, 1992. 365p.

COLLIS GEORGE, N.; SANDS, J.E. Moisture conditions for testing germination. Nature, London, v.190, n.4, p.367, 1961.

DELOUCHE, J.C. Influence of substrate moisture level and temperature on seed germination. Mississippi: State College, 1960 (mimeografado).

EIRA, M.T.S.; BARROS, A.S.R. Influência da quantidade de água no substrato sobre a germinação de sementes de pepino. In: CONGRESSO BRASILERO DE SEMENTES, 5., Gramado, 1987. Resumos... Brasilia: 1987. p.60.

ENGELHARDT, M.; VICENTE, M.; SILBERSCHMIDT, K. Water requiriments for optimum germination in corn (Zea mays). Arquivo do Instituto BiolGgico, Szo Paulo, v.33, n.3, p.95-112, 1966.

MARCOS FILHO, J.; CICERO, S.M.; SILVA, W.R. Araliagrio da Qualidade das Sementes. Piracicaba: FEALQ, 1987, 230p.

NORONHA, A.B.; VICENTE, M.; SILBERSCHMIDT, K.; ENGELHARDT, M. Water requirements for optimum germination in rice (Oryza sattva L.). Arquivo do Instituto Biológico, São Paulo, v.34, n.3, p. 243-251, 1967.

PETERSON, J.R.; COOPER, P.G. Some considerations of water in germination test. Seed Science \& Technology, Zurich, v.5, n.2, p.329-340, 1979.

PHANENDRANATH, B.R. Influence of amount of water in the paper towel on standard germination tests. Seed Science \& Technology, Zurich, v.5, n.2, p.82-87, 1980.

PMENTEL GOMES, F. Curso de Estatistica Experimental. 8.ed. Piracicaba: ESALQ/USP, 430p.

STILES, I.E. Relations of water to the germination of com and cotton seeds. Plant Physiology, Lancaster, v.23, n.1, p.201-222, 1949. 
TANAKA,M.A.S.; MARIANO, M.I.A; LEÃO, N.V.M. Influência da quantidade de água no substrato sobre a germinaçăo de sementes de amendoim. Revista Brasileira de Sementes, Brasilia, v.13, n.1, p.73-76, 1991.

TOLEDO, F.F.; CaRVAlHo, C.A. Quantidade de solução de nitrato de potassio e a germinaçăo de sementes de Brachlaria spp. Revista de Agricultura. Piracicaba, v.65, n.2, p.112-125, 1990.

TOLEDO, F.F.; PEDREIRA, A.A.S.. Quantidade de solução de nitrato de potássio e a germinação de sementes de capim Colonião. Revista Brasileira de Seruentes, Brasilia, v.6, n.1, p.61-70, 1984.
USBERTI, R. Nova metodologia para teste de germinaçăo de sementes de capim Colonião. Casa da Agricultura, São Paulo, v.3, n.1, p.12-16, 1981.

VICENTE, M.; ENGELHARDT, M.; SLBERSCHMIDT, K. Sobre a quantidade de agua ótima para a embebiçăo e germinaçăo de sementes. I. Estudo sobre milho, arroz e feijão. Angis da Academia Brasileira de Ciencias, São Paulo, v.33, n.3/4, p.409-428, 1969.

Recebido para publicação em 13.12 .93

Aceito para publicação em 12.03.94 